\title{
Effect of nursing position on incidence, type, and duration of clinically significant apnoea in preterm infants
}

\author{
L O Kurlak, N R Ruggins, T J Stephenson
}

\begin{abstract}
Aim - To investigate whether nursing position has any effect on the frequency, type, and duration of apnoeas in preterm infants.

Method - Thirty five preterm infants were entered into a crossover study and underwent polygraphic monitoring in each of two positions, prone and supine, the initial position being randomly allocated. Four parameters were recorded: nasal airflow, respiratory effort, electrocardiogram (ECG), and oxygen saturation. Each infant was studied in the two positions on the same day and each infant was studied only once. The studies were carried out on the neonatal intensive care unit.

Results - The infants were found to have significantly more central and mixed apnoeas in the supine than in the prone position. In addition, the severity of mixed apnoeas in terms of the duration of accompanying bradycardias and desaturations was greater in the supine than in the prone position (median difference $5 \cdot 1$ seconds in both instances). When considering the type of apnoea in relation to the duration, it was found that of those less than 20 seconds in duration there was a greater proportion that were central (25\%) compared with the proportion of central (5\%) apnoeas that were longer than 20 seconds. Of all the apnoeas that were less than 20 seconds in length, 16\% were obstructive and $59 \%$ were mixed, whereas of the apnoeas greater than 20 seconds, $13 \%$ were obstructive and $82 \%$ were mixed.

Conclusions - It appears that in addition to improving measures of lung function, the adoption of the prone nursing position for preterm infants may reduce associated problems of apnoea of prematurity.

(Arch Dis Child 1994; 71: F16-F19)
\end{abstract}

Department of Child

Health, University

Hospital, Nottingham

and Department of

Neonatal Medicine and

Surgery, City Hospital,

Nottingham

L O Kurlak

N R Ruggins

T J Stephenson

Correspondence to:

Dr L O Kurlak, Departmen

of Child Health, University

Hospital, Queen's Medical

Centre, Nottingham

NG7 2UH.

Accepted 15 March 1994 nursing position for preterm infants presents us with a clinical problem. There is a large body of evidence that points to the fact that the status of preterm infants with respiratory problems can be improved in terms of arterial oxygen tension, ${ }^{3}$ lung compliance, ${ }^{4}$ increased tidal volume, ${ }^{5}$ and lower energy expenditure ${ }^{6}$ when nursed prone. Apnoea of prematurity is a contributing factor to the respiratory problems of neonates as the oxygen desaturation that accompanies many of these events can have a profound deleterious effect on cardiovascular physiology. ${ }^{7-9}$ The frequency of apnoea of prematurity is such that there is a $95 \%$ probability that $85 \%$ or more of clinically healthy infants less than 34 weeks' gestation will have apnoeic episodes in the first 24 hours of life. ${ }^{10}$ Information on the effect of positioning on preterm infants having clinically significant apnoeic episodes is scarce and incomplete.

The objective of this study was to investigate whether nursing position has any effect on the incidence, type, and duration of clinically significant apnoea in preterm infants.

\section{Methods}

The study group consisted of well, preterm infants who had been identified as having clinically significant apnoeas and bradycardias. It is difficult to give an absolute definition of apnoea as there is little consensus between the different research groups. In this study we have chosen to consider all respiratory pauses longer than 20 seconds (as this is the designated alarm limit used on this neonatal unit) regardless of any other physiological change, and pauses shorter than 20 seconds only if accompanied by bradycardia down to less than 100 beats/min or an oxygen desaturation to less than $90 \%$, or both. Infants who needed assisted ventilation were not included.

A total of 35 infants was monitored for a median period of two hours (range one to four hours) after a feed in each of the two positions (prone and supine), the initial position having been randomly allocated. Any intervention to the infant such as drug administration or blood sampling was timed and noted. Cardiorespiratory monitoring was performed in the two positions on the same day for all infants and only one complete study was carried out on each infant. While prone, the infant's head was positioned to the side. Sleep state was not analysed during this study. The parameters monitored were nasal airflow, respiratory effort, electrocardiogram (ECG), and oxygen saturation, with all outputs being recorded on a four channel tape recorder (Racal Store 4DS, Racal Recorders Ltd). Nasal airflow at the nostril was measured using a self retaining nasal thermistor. 
Respiratory efforts were detected using respiratory inductive plethysmography (Respitrace system, Ambulatory Monitoring Inc) using one abdominal band. ${ }^{11}$ In this system breathing is detected by the changes in magnetic field induced by respiratory movement and its use has been evaluated for neonates. ${ }^{12}$

Oxygen saturation was monitored using pulse oximetry (Ohmeda Biox 3700 pulse oximeter, Ohmeda) with the flexiprobe sited over the dorsum of the infant's foot. The ECG signal was obtained from a Hewlett-Packard 78833B (Hewlett Packard) using a standard lead placement.

The polygraphic recordings obtained were viewed on a storage oscilloscope (Tektronix 7111, Tektronix Inc) and any suspected episodes were played back through a Gould six channel chart recorder (Gould Inc) at a paper speed of $5 \mathrm{~mm} / \mathrm{s}$. Manual analysis of the chart recordings was performed blind to the nursing position of the infant and produced data including the type and duration of apnoeic event, severity of bradycardia, and degree of arterial oxygen desaturation. The duration of bradycardia was defined as the length of time the heart rate was less than 100 beats $/ \mathrm{min}$, whereas the duration of oxygen desaturation was defined as the length of time the arterial oxygen saturation was less than baseline values. If the saturation levels did not return to the original baseline the point at which a new steady baseline was reached was used as the endpoint.

Statistical analysis of the data was performed on an Apple Macintosh computer system using Statview SE Graphics software. A null hypothesis was generated that 'nursing position has no effect on significant apnoea type'. To allow paired comparisons for each infant in the two nursing positions, data from each infant were analysed to find the median values for the cardiorespiratory changes recorded during central, obstructive, and mixed apnoeas. The changes in these values with nursing position were then compared using the Wilcoxon signed rank test for paired data.

Regarding the classification of apnoeas, central apnoeas were defined as those in which there was no detected respiratory effort and no detected nasal airflow; obstructive apnoeas were diagnosed where respiratory efforts were seen to continue but no airflow could be detected in the nasal airway; and mixed events were identified as those where a central pause was preceded or followed, or both, by obstructed breaths. Any episode which could not readily be classified into apnoea type was excluded from further analysis. This included

Table 1 Profile of apnoeas in relation to duration and nursing position. Values are absolute numbers of apnoeas

\begin{tabular}{|c|c|c|c|c|c|}
\hline \multirow[b]{3}{*}{ Type of apnoea } & \multicolumn{4}{|l|}{ Position } & \multirow{3}{*}{$\begin{array}{l}\text { Total } \\
\text { No }(\%) \\
(n=400)\end{array}$} \\
\hline & \multicolumn{2}{|l|}{ Supine } & \multicolumn{2}{|l|}{ Prone } & \\
\hline & $<19.9 \mathrm{~s}$ & $>20.0 \mathrm{~s}$ & $<19.9 s$ & $>20.0 \mathrm{~s}$ & \\
\hline $\begin{array}{l}\text { Central } \\
\text { Obstructive } \\
\text { Mixed } \\
\text { Unclassified }\end{array}$ & $\begin{array}{r}42 \\
14 \\
80 \\
3\end{array}$ & $\begin{array}{r}6 \\
8 \\
85\end{array}$ & $\begin{array}{r}12 \\
22 \\
49 \\
3\end{array}$ & $\begin{array}{r}2 \\
15 \\
59\end{array}$ & $\begin{array}{c}62(16) \\
59(15) \\
273(68) \\
6(2)\end{array}$ \\
\hline
\end{tabular}

any traces clearly affected by movement artefacts.

Episodes of periodic breathing were distinguished from central apnoeas by applying the definition that periodic breathing consists of regular cycles of respiration of approximately 10-18 seconds in length, interrupted by pauses of at least three seconds in duration, with this pattern recurring for at least two minutes. ${ }^{13}$

Approval for the study was given by the Nottingham ethics committee and in each instance informed written consent was obtained from the parents.

\section{Results}

The study group consisted of 35 infants with a median gestational age of 29 weeks (range 25-33) and median postnatal age of 15 days (range 3-49). Their median birth weight was $1180 \mathrm{~g}$ (range 690-2200). Ninety four per cent were receiving xanthines. The fact that most infants studied were receiving theophylline emphasises that the episodes were regarded as clinically significant by their doctors. Eight $(23 \%)$ infants were receiving supplementary oxygen via a headbox; for these infants the median oxygen requirement was $31 \%$ (range 20-58).

A total of 400 significant apnoeas was recorded, of which 394 were classified into either central, obstructive, or mixed, and six could not be categorised. Sixty two (16\%) were classified as central, $59(15 \%)$ as obstructive, and $273(68 \%)$ as mixed. The proportion of apnoea types differed with regard to apnoea duration (table 1). Only two infants showed a pattern of periodic breathing and these periods were disregarded from the analysis. One hundred and sixty two (41\%) apnoeas were recorded in the prone position whereas 238 $(60 \%)$ were in the supine position (table 1$)$. Our null hypothesis was that 'nursing position has no effect on significant apnoea type'. By evaluating the proportion of each type of apnoea in each infant and performing a Wilcoxon signed rank test on these proportions, it was found that there were significantly more central $(p=0.025)$ and mixed $(p=0.012)$ apnoeas in the supine than in the prone position.

These results indicate that the occurrence of apnoea type is affected by the position in which the infant is nursed. Therefore, the null hypothesis was rejected.

No significant difference was found with respect to the magnitude of cardiorespiratory changes occurring during obstructive and central apnoeas in either of the two positions. In contrast, during mixed apnoeas, which make up $68 \%$ of significant episodes recorded, the infants had greater decreases in heart rate $(p=0.02)$, longer duration of bradycardia $(p=0.0003)$, and longer accompanying desaturations $(p=0.03)$ while nursed supine than while nursed prone. These changes were observed despite the fact that the mixed apnoea durations were not different in either position, implying that the difference in severity of the physiological changes could not 
Table 2 p Values for paired analyses (in each infant, supine $\mathrm{v}$ prone) of the difference in the median values for each parameter during mixed apnoeas. In all comparisons in which $p<0.05$, there is a statistically significant difference between the supine and prone positions, with the supine position having the more severe consequences

\begin{tabular}{llc}
\hline & $\begin{array}{l}p \\
\text { Values }\end{array}$ & $\begin{array}{l}\text { Difference in } \\
\text { median values }\end{array}$ \\
\hline Duration of apnoea (sec) & $0 \cdot 1$ & $0 \cdot 7$ \\
Decrease in oxygen saturation (\%) & $0 \cdot 1$ & $4 \cdot 5$ \\
Duration of oxygen desaturation (sec) & $0 \cdot 03$ & $5 \cdot 1$ \\
Decrease in heart rate (beats/min) & $0 \cdot 02$ & $18 \cdot 0$ \\
Duration of bradycardia (sec) & $0 \cdot 0003$ & $5 \cdot 1$ \\
\hline
\end{tabular}

be attributed to mixed apnoeas being longer in one of the two positions (see table 2).

\section{Discussion}

Previous studies addressing the question of the effect of positioning on the occurrence of apnoeic events have conflicting conclusions. Orr et al made the observation that sleeping position did not significantly affect the rate or duration of central and obstructive apnoeas. ${ }^{14}$ In addition, they found that mixed events were so rare that they excluded these data from their final analysis. These findings are difficult to interpret as the infants that were studied were mainly term or, if born preterm, were at a postnatal age such that the observations would probably more closely resemble those of full term neonates. In contrast, Heimler et al observed an increase in the overall incidence of apnoea in the supine than in the prone position, this increase presenting as an increase in the number of central apnoeic events. ${ }^{15}$

In the present study, the distribution of types of apnoea was such that $16 \%$ of the total events were central and $15 \%$ were obstructive, whereas most $(68 \%)$ clinically significant events were mixed. This agrees with a number of published findings. ${ }^{1617}$ In addition, we have shown that the profile of the apnoea types differs according to the duration of events (table 1); a larger proportion of the shorter episodes is central or obstructive, whereas the longer events, greater than 20 seconds in duration, are more likely to be mixed in nature. The fact that longer apnoeas are more likely to be mixed has previously been observed. ${ }^{18}$ In agreement with previous studies ${ }^{15}$ we found that there is a significant increase in central apnoeas in the supine position; in addition, we have shown a significantly greater number of mixed apnoeas in infants having apnoeas while nursed supine.

This study was not designed to investigate mechanisms. One reason for this observed difference could be the occurrence of occult gastro-oesophageal reflux, which is known to be more severe in symptomatic infants nursed supine. ${ }^{1920}$ Research into the problem of gastro-oesophageal reflux in preterm infants with theophylline resistant apnoea has shown that nursing these infants prone results in an improvement in the number of apnoeic episodes experienced, which can be maintained even when the xanthine treatment is removed. ${ }^{21}$ In more mature preterm neonates there does not appear to be a clear association between reflux and apnoeas. ${ }^{22}$ Of the three classes of apnoea (central, obstructive, and mixed), obstructive apnoeas have been implicated in the problem of sudden infant death syndrome, with near miss infants having increased numbers of obstructive apnoeas in the period after the near miss episode, ${ }^{23}$ now referred to as an apparent life threatening event. There are several indicators that position may be implicated in the mechanisms of occurrence of apnoea. Neck flexion may cause upper airway obstruction while supine, ${ }^{24}$ which may predispose newborn infants to obstructive apnoeas in this position. Gastrooesophageal reflux has been associated with the occurrence of apnoeic episodes in the supine position, ${ }^{25-27}$ possibly due to stimulation of the laryngochemoreceptors, though workers disagree as to whether there is a direct causal relation.

Although the occurrence of apnoeic events has been identified in infants with a history of apparent life threatening events there is no evidence of a direct link between apnoea of prematurity and sudden infant death syndrome.

It is obviously not enough to merely consider the number and type of episodes of apnoea occurring in each of the two nursing positions. Clearly, it is the cardiovascular consequences of these episodes which have to be considered when deciding whether there are advantages of one position over the other. The systemic haemodynamic events associated with apnoea have been described elsewhere. ${ }^{78}$

The cerebral haemodynamic events appear to reflect systemic haemodynamic events with a prominent decrease in cerebral blood flow and blood pressure occurring with apnoea and severe bradycardia. ${ }^{9}$ In light of the fact that repeated episodes of severe bradycardia (heart rate less than 80 beats $/ \mathrm{min}$ ) could possibly cause or exacerbate hypoxic-ischaemic brain injury, ${ }^{9}$ it is important that appropriate measures are taken to reduce the possibility of this occurring. Our findings (the longer the duration of bradycardias, the greater the decrease in heart rate and the longer the duration of oxygen desaturation during mixed apnoeas in the supine position) strengthen the view that the status of this group of preterm infants with significant apnoea of prematurity can be improved by nursing them in a prone position.

Further investigations into the causes of these differences related to position are necessary and may lead to a better understanding of the pathophysiological mechanisms underlying apnoea of prematurity.

1 Fleming P, Gilbert R, Azaz Y, et al. Interaction between bedding and sleeping position in the sudden infant death byndrome: a population based case-control study. $B M F$ syndrome: a popula

2 Wigfield R, Fleming P, Berry J, Rudd P, Golding J. Can the fall in Avon's sudden infant death rate be explained by the changes in sleeping position? BMF 1992; 304: $282-3$.

3 Martin R, Herrell N, Rubin D, Fanaroff A. Effect of supine and prone positions on arterial oxygen tension in the preterm infant. Pediatrics 1979; 63: 528-31.

4 Wagaman M, Shutack J, Moomjian A, Schwartz J, Shaffer $T$, Fox W. Improved oxygenation and lung compliance with prone positioning of neonates. $\mathcal{F}$ Pediatr 1979; 94: 787-91. 
5 Hutchison A, Ross K, Russell G. The effect of posture on ventilation and lung mechanics in preterm and light-forventilation and lung mechanics in preter

6 Masterson J, Zucker C, Schulze K. Prone and supine positioning effects on energy expenditure and behaviou of low birth weight neonates. Pediatrics 1987; 80: 689-92.

7 Girling D. Changes in heart rate, blood pressure, and pulse pressure during apnoeic attacks in newborn babies. Arch Dis Child 1972; 47: 405-10

8 Storrs N. Cardiovascular effects of apnoea in preterm infants. Arch Dis Child 1977; 52: 534-40.

9 Perlman J, Volpe J. Episodes of apnoea and bradycardia in the preterm newborn: impact on cerebral circulation. the preterm newborn: im
Pediatrics 1985 ; 76: 333-8.

10 Barrington K, Finer N. The natural history of the appearance of apnea of prematurity. Pediatr Res 1991; 29: appearanci.

11 Upton C, Milner A, Stokes G. Combined impedance and inductance for the detection of apnoea of prematurity. Early Hum Dev 1990; 24: 55-63.

12 Duffty P, Spriet L, Bryan M, Bryan A. Respiratory induction plethysmooraphy (Respitrace TM): an evaluation of its use in the infant. Am Rev Respir Dis 1981; 123: 542-6.

13 Miller M, Martin R. Pathophysiology of apnoea of prematurity. In: Polin R, Fox W, eds. Fetal and neonatal physiturity. In: Polin R, Fox W, eds. Fetal and neonatal physi-
ology. Vol 1. Philadelphia: WB Saunders, 1992: 872-85.

14 Orr W, Stahl M, Duke J, et al. Effect of sleep and position on the incidence of obstructive and central apnoea in on the incidence of obstructive and
infants. Pediatrics $1985 ; 75: 832-5$.

15 Heimler R, Langlois J, Hodel D, Nelin L, Sasidharan P. Effect of positioning on the breathing pattern of preterm infants. Arch Dis Child 1992; 67: 312-4.

16 Dransfield D, Spitzer A, Fox W. Episodic airway obstruction in premature infants. Am 7 Dis Child 1983; 137: 441-3.

17 Miller M, Carlo W, Martin R. Continuous positive airway pressure selectively reduces obstructive apnea in preterm infants. F Pediatr 1985; 106: 91-4.

18 Butcher-Puech $M$, Henderson-Smart D, Holley D, Lacey J. Relation between apnoea duration and type and neurological status of preterm infants. Arch Dis Child 1985; 60: 953-8.

19 Vandenplas Y, Sacre-Smits L. Seventeen hour continuous esophageal $\mathrm{pH}$ monitoring in the newborn: evaluation of the influence of position in babies. $\mathcal{f}$ Pediatr Gastroenterol Nutr 1985; 4: 356-61.

20 Blumenthal I, Lealman G. Effect of posture on gastrooesophageal reflux in the newborn. Arch Dis Child 1982; 57: 555-6.

21 Newell S, Booth I, Durbin G, McNeish A. Gastrooesophageal reflux in preterm infants. Arch Dis Child

22 Ajuriaguerra Md, Radvanyi-Bouvet M, Huon C, Moriette $G$. Gastroesophageal reflux and apnea in prematurely born infants during wakefulness and sleep. Am $\mathcal{f}$ Dis Child 1991; 145: 1132-6.

23 Guilleminault C, Ariagno R, Forno L, Nagel L, Baldwin R, Owen $M$. Obstructive sleep apnea and near miss for SIDS: 1 . Report of an infant with sudden death. Pediatrics 1979; 63: 837-43.

24 Stark A Thach B. Mechanisms of airway obstruction leading to apnea in newborn infants. $\Im$ Pediatr $1976 ; 89$ leading

25 Herbst J, Minton S, Book L. Gastroesophageal reflux causing respiratory distress and apnea in newborn infants. f Pediatr 1979; 95: 763-8.

26 Walsh J, Farrell M, Keenan W, Lucas M, Kramer M. Gastroesophageal reflux in infants: relation to apnea. f Pediatr 1981; 99: 197-201.

27 Menon A, Schefft G, Thach B. Apnea associated with regurgitation in infants. 7 Pediatr 1985; 106: 625-9. 